\title{
Optimal Waist Circumference Cut-Off Point for Multiple Risk Factor Aggregation: Results from the Maracaibo City Metabolic Syndrome Prevalence Study
}

\author{
Valmore Bermúdez, ${ }^{1}$ Joselyn Rojas, ${ }^{1}$ Juan Salazar, ${ }^{1}$ Roberto Añez, ${ }^{1}$ \\ Mervin Chávez-Castillo, ${ }^{1}$ Robys González, ${ }^{1}$ María Sofía Martínez, ${ }^{1}$ Mayela Cabrera, \\ Clímaco Cano, ${ }^{1}$ Manuel Velasco, ${ }^{2}$ and José López-Miranda ${ }^{3}$ \\ ${ }^{1}$ Endocrine and Metabolic Diseases Research Center, The University of Zulia, 20th Avenue, Maracaibo 4004, Venezuela \\ ${ }^{2}$ Clinical Pharmacology Unit, José María Vargas School of Medicine, Central University of Venezuela, Caracas 1051, Venezuela \\ ${ }^{3}$ Lipid and Atherosclerosis Unit, Department of Medicine, Carlos III Institute of Health, IMIBIC/Reina Sofia University \\ Hospital/University of Córdoba and CIBER Obesity and Nutrition Physiopathology (CIBEROBN), Córdoba 230002, Spain
}

Correspondence should be addressed to Valmore Bermúdez; valmore@gmail.com

Received 16 September 2014; Revised 21 November 2014; Accepted 24 November 2014; Published 9 December 2014

Academic Editor: Suminori Kono

Copyright (C) 2014 Valmore Bermúdez et al. This is an open access article distributed under the Creative Commons Attribution License, which permits unrestricted use, distribution, and reproduction in any medium, provided the original work is properly cited.

Context and Objective. The purpose of this study was to determine optimal waist circumference (WC) cut-off values for the detection of multiple risk factor aggregation in individuals from Maracaibo, Venezuela. Participants and Methods. A total of 1,902 adult individuals of both genders belonging to MMSPS were included. Complete physical, laboratory, and anthropometric examination were done to evaluate Metabolic Syndrome (MS) components and insulin resistance. ROC curves were plotted for risk factor aggregation in order to assess WC cut-off point. Logistic regression models were constructed to assess risk factors associated with the WC. Results. There were $52.2 \%$ females and $47.8 \%$ males, with WC of $90.7 \pm 13.7 \mathrm{~cm}$ and $98.2 \pm 15.9 \mathrm{~cm}$, respectively. ROC curves exhibited a WC cut-off point for women of $90.25 \mathrm{~cm}(68.4 \%$ sensitivity, $65.8 \%$ specificity) and $95.15 \mathrm{~cm}(71.1 \%$ sensitivity, $67.4 \%$ specificity) for men. HOMA2-IR and high blood pressure were associated with a WC over these cut-off points, as well as 2.5-fold risk increase for multiple risk factor aggregation (OR 2.56; CI 95\%: 2.05-3.20; $P<0.01$ ). Conclusions. These populationspecific WC cut-offs are readily applicable tools for detection of risk factor aggregation. Insulin resistance is closely associated with this definition of abdominal obesity, which may serve as a surrogate for its assessment.

\section{Introduction}

Metabolic Syndrome (MS) is a cluster of endocrine-metabolic disturbances which increases the risk of developing Cardiovascular Disease (CVD) and type 2 diabetes mellitus (T2DM) [1]. In recent years its prevalence has increased worldwide, especially in Latin America where it has become a public health issue, fueled by the sociocultural backdrop and psychobiologic habits pertaining to this region $[2,3]$. In an attempt to "harmonize" MS diagnostic criteria, organizations such as the International Diabetes Federation, National Heart, Lung, Blood Institute, American Heart Association, and others (IDF/NHLBI/AHA-2009) agreed on an integrated set of diagnostic criteria that may be widely utilized worldwide, and whose clinical application would allow for the identification of subjects in risk of further cardiometabolic disease [4].

Despite efforts to standardize criteria for this entity, waist circumference (WC) is still the most controversial variable in the MS definition due to the absence of specific cut-off points for Latin-Americans, Sub-Saharan Africans, Eastern Mediterranean, and Middle East (Arab) populations. Therefore, when the International Diabetes Federation exposed their criteria for MS diagnosis in 2005 (IDF-2005) [5], they suggested that when using this criterion in South American countries, researchers should rely on cut-off points from 
the South Asia (90 cm for men and $80 \mathrm{~cm}$ for women) until more data would be obtained from such countries. Such point of view is maintained in the IDF/NHLBI/AHA-2009, supporting the notion that these WC references might not reflect the real epidemiologic behavior of obesity.

Given the latest recommendations by the IDF/NHLBI/ AHA-2009 consensus, several research groups have started to select population-specific WC cutpoints that would properly aid in the detection of cardiometabolic disease, such as the work from Mansour et al. [6] conducted in a rural Iraqi setting (WC in women: $99 \mathrm{~cm}$ and in men: $97 \mathrm{~cm}$ ), Delavari et al. [7] in Iran (WC in women: $89 \mathrm{~cm}$ and in men: $91 \mathrm{~cm}$ ), and Motala et al. [8] in a rural community from South Africa (WC in women: $86 \mathrm{~cm}$ and in men: $92 \mathrm{~cm}$ ). The overall approach [6-8] was the application of ROC curve construction to determine cutpoints for WC and metabolic component aggregation in order to define individuals who are healthy or sick.

We previously investigated the prevalence of obesity using Body Mass Index (BMI) and WC as surrogates for both, total and abdominal adiposity [9]. The results were quite alarming with $33.3 \%$ obesity and $34.8 \%$ overweight when BMI classification was used, and $74.2 \%$ obesity when applying the IDF/NHLBI/AHA-2009 criteria, suggesting the possibility that the latest consensus might be associated with overestimation of obesity in our population, with particular ethnic, genetic background and sociocultural traits which would influence such prevalence [9]. Consequently, due to the lack of properly determined and populationspecific WC cutpoints in Venezuela, we decided to determine gender-specific WC cutpoints to diagnose abdominal obesity and enhance accuracy of MS identification in an obesityburdened locality such as ours.

\section{Research Design and Methods}

2.1. Subject Selection. The Maracaibo City Metabolic Syndrome Prevalence Study (MMSPS) [10] is a cross-sectional study undertaken in the city of Maracaibo-Venezuela, the second largest city in the country with 2.500 .000 inhabitants, with the purpose of identifying and analyzing MS and cardiovascular risk factors in the adult population of Maracaibo. A total of 2,230 subjects were enrolled, out of which 1,902 were selected after the exclusion of individuals without serum insulin levels determination, and those with a previous diagnosis of T2DM because current pharmacological and nonpharmacological intervention would alter the variables evaluated in this investigation. The study was approved by the Bioethics Committee of the Endocrine and Metabolic Diseases Research Center, University of Zulia, and all participants signed a written consent before being interrogated and physically examined by a trained team.

2.2. Clinical Analysis. All participants were subject to a complete physical examination, physical evaluation, and anthropometric measurements. The information that was obtained from anamnesis included socioeconomic data, education and working status, ethnicity, and smoking and drinking habit. Assessment of blood pressure was done using a calibrated mercury sphygmomanometer, with patients previously rested (during at least 15 minutes) in a sitting position with both feet touching the floor; the arm was positioned at heart level; a proper sized cuff was used for the procedure. WC was evaluated using calibrated measuring tapes in accordance with the USA National Institutes of Health protocol [11]. For the quantification of Body Mass Index (BMI), the $\left[\right.$ weight $/$ height $\left.^{2}\right]$ formula was utilized and results were expressed in $\mathrm{kg} / \mathrm{m}^{2}$ [12].

2.3. Laboratory Analysis. An antecubital blood sample was taken following an overnight fasting of 8-12 hours in order to measure the following: fasting blood glucose, total cholesterol, triacylglycerides (TAG), and HDL-C with an enzymatic colorimetric technique and a computerized analyzer (Human, Magdeburg, Germany). Serum fasting insulin was determined using an ultrasensitive ELISA double-sandwich method (DRG Instruments GmbH, Germany, Inc). Insulin resistance (HOMA2-IR index) was calculated using the software HOMA Calculator v2.2.2 supplied by the Oxford Center for Diabetes Endocrinology and Metabolism available at https://www.dtu.ox.ac.uk/homacalculator/download.php which requires fasting insulin and glycemia for proper program calculation.

2.4. Clinical Definitions. Presence of insulin resistance (IR) in our population was defined as HOMA2-IR $\geq 2$ [13]. Diagnosis of MS was done using the IDF/NHLBI/AHA-2009 consensus [4]. Multiple risk factor aggregation (MRFA) was defined as $\geq 2$ of the following: high blood pressure (Systolic Blood Pressure $\geq 130 \mathrm{mmHg}$ and/or Diastolic Blood Pressure $\geq$ $85 \mathrm{mmHg}$; or history of antihypertensive usage), impaired fasting glucose $(\geq 100 \mathrm{mg} / \mathrm{dL}$ or presence of diagnosis of T2DM), high TAG $(\geq 150 \mathrm{mg} / \mathrm{dL}$ or presence of treatment for this disorder), and low HDL-C $(<40 \mathrm{mg} / \mathrm{dL}$ in males and $<50 \mathrm{mg} / \mathrm{dL}$ in females or presence of treatment for this disorder), similar to the definition used in the South African community by Motala et al. [8] and the state of risk factor clustering proposed by Hara et al. [14].

2.5. Statistical Analysis. Statistical analysis was done using the Statistical Package for the Social Sciences (SPSS) v19 for Windows (IBM Inc. Chicago, IL). Normal distribution of continuous variables was evaluated by using Geary's test. For normally distributed variables, the results were expressed as arithmetic mean \pm SD. Variables without a normal distribution were logarithmically transformed and normal distribution later corroborated. Differences between arithmetic means were assessed using Student's $t$-test (when two groups were compared) or ANOVA (when three or more groups were compared). Qualitative variables were expressed as absolute and relative frequencies, while $\chi^{2}$ test was applied for association determination, considering the results statistically significant when $P<0.05$.

The Receiving Operating Characteristic (ROC) curves were constructed to expect presence of MRFA or $\geq 2$ metabolic components for MS [4], with the exception of WC. ROC curves were plotted for each gender using R Project software for Statistical Computing. Several indexes were calculated to assess the optimal cut-off point on the curve, 
TABLE 1: General characteristics of the general population according to gender, Maracaibo, 2014.

\begin{tabular}{|c|c|c|c|c|c|c|}
\hline & \multicolumn{2}{|c|}{ Females $(n=992)$} & \multicolumn{2}{|c|}{ Males $(n=910)$} & \multicolumn{2}{|c|}{ Total $(n=1902)$} \\
\hline & $n$ & $\%$ & $n$ & $\%$ & $n$ & $\%$ \\
\hline \multicolumn{7}{|l|}{ Ethnic groups } \\
\hline Mixed & 757 & 76.3 & 706 & 77.6 & 1463 & 76.9 \\
\hline Hispanic white & 162 & 16.3 & 138 & 15.2 & 300 & 15.8 \\
\hline Afro-Venezuelan & 24 & 2.4 & 31 & 3.4 & 55 & 2.9 \\
\hline Amerindian & 39 & 3.9 & 34 & 3.7 & 73 & 3.8 \\
\hline Others & 10 & 1.0 & 1 & 0.1 & 11 & 0.6 \\
\hline \multicolumn{7}{|l|}{ Age groups (years) } \\
\hline$<20$ & 87 & 8.8 & 70 & 7.7 & 157 & 8.3 \\
\hline $20-29$ & 218 & 22.0 & 294 & 32.3 & 512 & 26.9 \\
\hline $30-39$ & 176 & 17.7 & 178 & 19.6 & 354 & 18.6 \\
\hline $40-49$ & 230 & 23.2 & 164 & 18.0 & 394 & 20.7 \\
\hline $50-59$ & 170 & 17.1 & 136 & 14.9 & 306 & 16.1 \\
\hline $60-69$ & 74 & 7.5 & 46 & 5.1 & 120 & 6.3 \\
\hline$\geq 70$ & 37 & 3.7 & 22 & 2.4 & 59 & 3.1 \\
\hline Metabolic Syndrome* & 365 & 36.8 & 390 & 42.9 & 755 & 39.7 \\
\hline High blood pressures & 324 & 32.7 & 379 & 41.6 & 703 & 37 \\
\hline Impaired fasting glucose $\mathrm{e}^{\ddagger}$ & 216 & 21.8 & 243 & 26.7 & 459 & 24.1 \\
\hline High triacylglycerides ${ }^{\Psi}$ & 206 & 20.8 & 290 & 31.9 & 496 & 26.1 \\
\hline Low HDL-cholesterol ${ }^{¥}$ & 624 & 62.9 & 451 & 49.6 & 1075 & 56.5 \\
\hline Elevated waist circumference ${ }^{\S}$ & 779 & 78.5 & 638 & 70.1 & 1417 & 74.5 \\
\hline Multiple risk factor aggregation $^{\dagger}$ & 395 & 39.8 & 429 & 47.1 & 824 & 43.3 \\
\hline Total & 992 & 52.2 & 910 & 47.8 & 1902 & 100 \\
\hline
\end{tabular}

${ }^{*}$ Criteria from the IDF/AHA/NHLBI-2009 consensus.

'Systolic Blood Pressure $\geq 130 \mathrm{mmHg}$ and/or Diastolic Blood Pressure $\geq 85 \mathrm{mmHg}$ or history of antihypertensive usage.

$\ddagger \geq 100 \mathrm{mg} / \mathrm{dL}$ or presence of diagnosis of type 2 diabetes.

$\Psi \geq 150 \mathrm{mg} / \mathrm{dL}$ or presence of treatment for this disorder.

$¥<40 \mathrm{mg} / \mathrm{dL}$ in males and $<50 \mathrm{mg} / \mathrm{dL}$ in females or presence of treatment for this disorder.

$\$<90 \mathrm{~cm}$ in males and $<80 \mathrm{~cm}$ in females.

${ }^{\dagger}$ Defined as $\geq 2$ of the following: high blood pressure, impaired fasting glucose, high triacylglycerides, low HDL-cholesterol.

and hence the best WC cut-off value. The Youden Index was calculated using $[J=$ sensitivity + specificity $-1=S-(1-E s)]$ [15], by yielding the true positive rate (sensitivity) and false positive rate $(1-$ specificity) when $J>1$. The minimal cut-off value was calculated using the distance of the point closest to (0.1) on the ROC curve formula: square root [( 1 - sensitivity $) 2$ $+(1-$ specificity $) 2]$ [16]. Moreover, positive [sensitivity/1 specificity] and negative [ 1 - sensitivity/specificity] likelihood ratios were calculated to aid in the selection of the cutoff alongside Youden Index; likelihood ratios $>1$ indicate association with the disease, whereas ratios $<1$ indicate association with the absence of the disease [17].

Two logistic regression models were calculated: (a) one model for risk factors associated with abdominal obesity according to obtained cut-off points, and (b) a second one for risk factors associated with MRFA (Dependent Variable).

\section{Results}

A total of 1,902 subjects were studied: $52.2 \%$ females and $47.8 \%$ males. The arithmetic mean of age was $38.7 \pm 15.0$ years; whereas the mean WC was $90.7 \pm 13.7 \mathrm{~cm}$ in females, and $98.2 \pm 15.9 \mathrm{~cm}$ in males, $P<0.0001$. The prevalence of MS in the general population was $39.7 \%$, with $36.8 \%$ among females and $42.9 \%$ among males. The prevalence of MRFA ( $\geq 2$ MS factors) was $43.3 \%$, with $39.8 \%$ in females and $47.1 \%$ in males. The most prevalent risk factors were abdominal obesity (74.5\%) and low HDL-C levels (56.5\%), seemly more frequent in the female group; the rest of the metabolic features of the population sample are described in Table 1.

On the other hand, clinical characteristics and biochemical results are observed in Table 2. ROC curves were plotted for both genders to determine the cut-off values of WC in relation to MRFA (Figure 1). According to the ROC curves, the cut-offs yielding the best predictive values for such status was $90.25 \mathrm{~cm}$ for women, with $68.4 \%$ sensitivity and $65.8 \%$ specificity (AUC: 0.716 ; CI $95 \%, 0.684-0.748$ ), and $95.15 \mathrm{~cm}$, with $71.1 \%$ sensitivity and $67.4 \%$ specificity (AUC: 0.746; CI 95\%, 0.715-0.778) for men. Likewise, Table 3 shows the cut-off points for each ethnic group in our sample, while abdominal obesity prevalence comparison according to IDF/NHLBI/AHA-2009 and our cutpoints are observed in 
TABLE 2: Clinical and biochemical parameters evaluated by gender, Maracaibo, 2014.

\begin{tabular}{|c|c|c|c|}
\hline & $\begin{array}{l}\text { Females } \\
(n=992)\end{array}$ & $\begin{array}{c}\text { Males } \\
(n=910)\end{array}$ & \multirow[t]{2}{*}{$P^{*}$} \\
\hline & Mean \pm SD & Mean \pm SD & \\
\hline Age (years) & $40.1 \pm 15.4$ & $37.1 \pm 14.4$ & $7.15 \times 10^{-5}$ \\
\hline Body Mass Index $\left(\mathrm{Kg} / \mathrm{m}^{2}\right)$ & $27.8 \pm 6.2$ & $28.7 \pm 6.3$ & 0.001 \\
\hline Waist circumference $(\mathrm{cm})$ & $90.7 \pm 13.7$ & $98.2 \pm 15.9$ & $4.2 \times 10^{-28}$ \\
\hline Fasting glycemia (mg/dL) & $93.9 \pm 17.4$ & $94.3 \pm 21.5$ & 0.911 \\
\hline Fasting insulin (UI/mL) & $14.4 \pm 9.2$ & $14.7 \pm 9.8$ & 0.526 \\
\hline HOMA2-IR & $2.13 \pm 1.30$ & $2.16 \pm 1.41$ & 0.530 \\
\hline TAG (mg/dL) & $113.1 \pm 79.7$ & $139.1 \pm 100.4$ & $9.3 \times 10^{-13}$ \\
\hline VLDL-cholesterol (mg/dL) & $23.4 \pm 17.5$ & $28.7 \pm 22.8$ & $1.5 \times 10^{-9}$ \\
\hline Total cholesterol (mg/dL) & $193.6 \pm 44.4$ & $187.7 \pm 47.6$ & 0.001 \\
\hline HDL-cholesterol (mg/dL) & $47.2 \pm 11.9$ & $41.1 \pm 11.4$ & $7.9 \times 10^{-34}$ \\
\hline LDL-cholesterol (mg/dL) & $123.6 \pm 37.6$ & $119.1 \pm 38.9$ & 0.005 \\
\hline $\mathrm{SBP}(\mathrm{mmHg})$ & $116.9 \pm 17.2$ & $121.6 \pm 15.9$ & $3.7 \times 10^{-11}$ \\
\hline DBP (mmHg) & $75.3 \pm 10.8$ & $78.6 \pm 11.6$ & $5.5 \times 10^{-12}$ \\
\hline
\end{tabular}

(*) Student's $t$-test (after logarithmic transformation).

$\mathrm{SD}=$ standard deviation; TAG = triacylglycerides; VLDL-cholesterol = very low density lipoprotein; HDL-cholesterol = high density lipoprotein; LDLcholesterol = low density lipoprotein; $\mathrm{SBP}=$ systolic blood pressure; $\mathrm{DBP}=$ diastolic blood pressure .

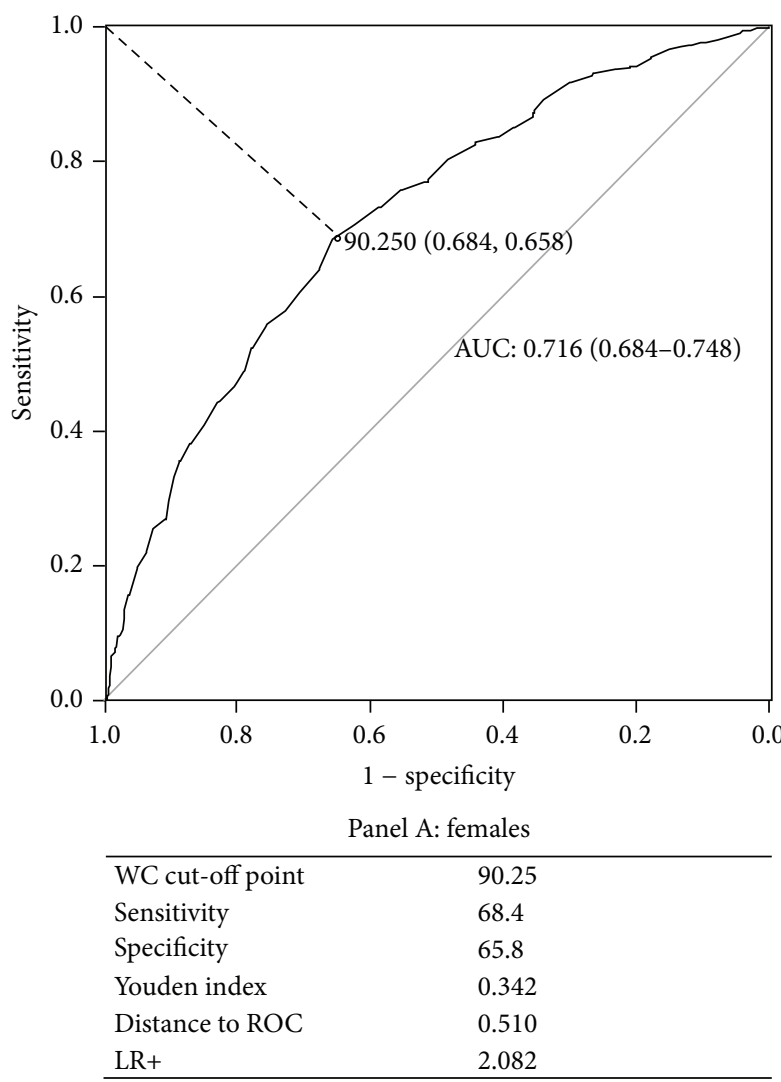

(a)

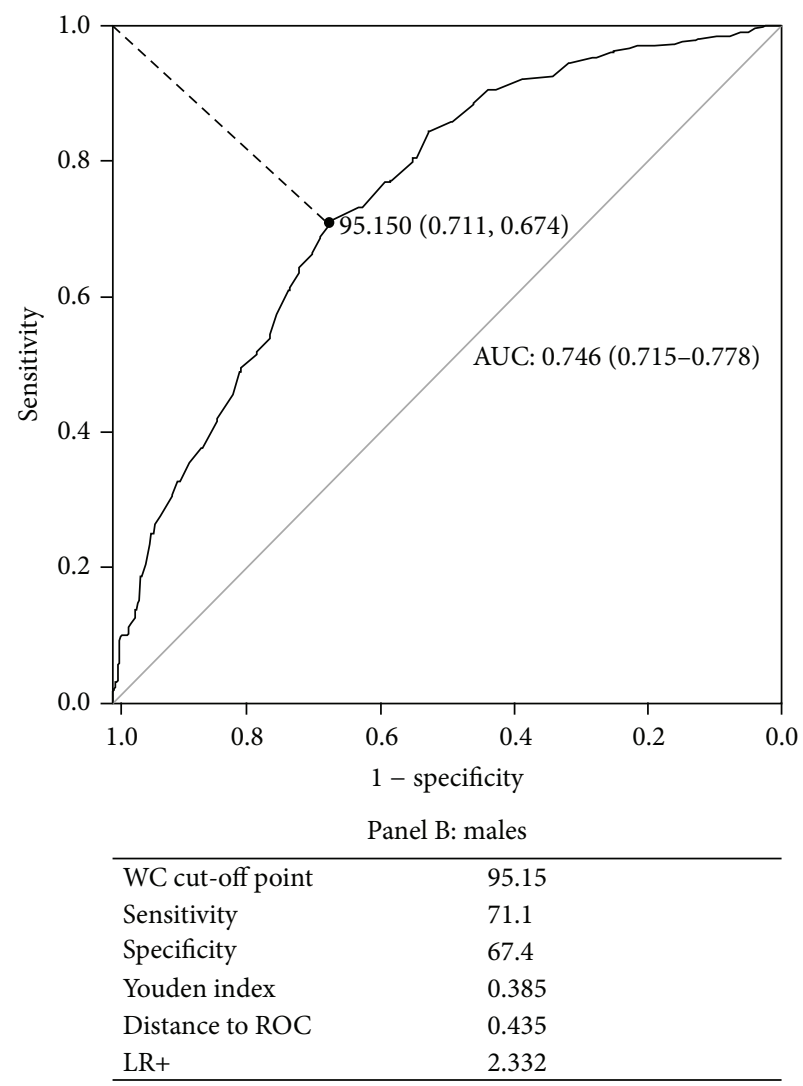

(b)

FIGURE 1: ROC curves constructed to determine waist circumference cut-off points for the detection of multiple risk factor aggregation in the general population according to gender, Maracaibo, 2014. 
TABLE 3: Waist circumference cutpoints for abdominal obesity and BMI according to ethnic groups, Maracaibo, 2014.

\begin{tabular}{|c|c|c|c|c|}
\hline & \multicolumn{4}{|c|}{ Ethnic groups ${ }^{*}$} \\
\hline & Mixed race & Hispanic whites & Afro-Venezuelan & Amerindian \\
\hline Females & $n=757$ & $n=162$ & $n=24$ & $n=39$ \\
\hline WC cut-offs point $(\mathrm{cm})$ & 90.25 & 90.5 & 91.5 & 85.5 \\
\hline AUC (CI 95\%) & $0.713(0.676-0.751)$ & $0.679(0.595-0.762)$ & $0.653(0.423-0.882)$ & $0.835(0.704-0.965)$ \\
\hline Sensitivity (\%) & 68 & 68.1 & 75 & 75 \\
\hline Specificity (\%) & 67.8 & 54.8 & 50 & 74.1 \\
\hline Youden Index & 0.36 & 0.23 & 0.25 & 0.49 \\
\hline Distance to ROC & 0.454 & 0.553 & 0.559 & 0.359 \\
\hline $\mathrm{LR}+$ & 2.111 & 1.507 & 1.5 & 2.896 \\
\hline $\operatorname{BMI}\left(\mathrm{Kg} / \mathrm{m}^{2}\right)^{*}$ & $27.6 \pm 6.3$ & $28.5 \pm 6.4$ & $28.9 \pm 5.7$ & $25.9 \pm 5.3$ \\
\hline Males & $n=706$ & $n=138$ & $n=31$ & $n=34$ \\
\hline WC cut-offs point $(\mathrm{cm})$ & 95.15 & 95.5 & 91.25 & 89.5 \\
\hline AUC (CI 95\%) & $0.737(0.701-0.773)$ & $0.783(0.707-0.860)$ & $0.821(0.665-0.976)$ & $0.729(0.538-0.920)$ \\
\hline Sensitivity (\%) & 71.1 & 78.9 & 81.3 & 90 \\
\hline Specificity (\%) & 65.8 & 67.2 & 80 & 70.8 \\
\hline Youden Index & 0.37 & 0.46 & 0.61 & 0.61 \\
\hline Distance to ROC & 0,448 & 0.390 & 0.274 & 0.309 \\
\hline $\mathrm{LR}+$ & 2.079 & 2.405 & 4.065 & 3.082 \\
\hline $\operatorname{BMI}\left(\mathrm{Kg} / \mathrm{m}^{2}\right)^{* *}$ & $28.9 \pm 6.4$ & $29.2 \pm 5.6$ & $27.3 \pm 7.4$ & $25.6 \pm 4.6$ \\
\hline
\end{tabular}

Youden Index $=$ Sensitivity + Specificity -1.

$\mathrm{LR}+=$ (positive likelihood ratio).

$\mathrm{BMI}=$ Body Mass Index.

* One way-ANOVA $=0.076$

** One way-ANOVA $=0.011$ : Post Hoc Tukey: mixed race versus Amerindian: $P=0.018$; Hispanic whites versus Amerindian: $P=0.015$.

Figure 2, with a resulting decline in percentages obtained in the overall sample and according to sex $(P<0.05)$.

The main metabolic risk factors associated with a high WC are shown in Table 4, being IR the variable with the greatest association (OR: 3.10; CI 95\%: 2.37-3.83; $P<0.01$ ), followed by high blood pressure (OR: 2.38; CI 95\%: 1.87-3.05; $P<0.01)$. Table 5 displays the results for MRFA using the proposed WC cut-off points. The results showed that subjects with obesity determined by our WC cut-off points have 2.5 times more risk for metabolic risk aggregation (OR 2.56; CI 95\%: 2.05-3.20; $P<0.01)$. This risk is slightly higher than that obtained with IR (OR 2.30; CI 95\%: 1.85-2.86; $P<0.01$ ), but lower than those obtained from several age groups, like 40-49 years (OR 3.54; CI 95\%: 2.21-5.69; $P<0.01$ ), 50-59 years (OR 4.44; CI 95\%: 2.72-7.25; $P<0.01$ ), 60-69 years (OR 6.84; CI 95\%: 3.78-12.38; $P<0.01$ ), and $\geq 70$ years (OR 8.22; CI 95\%: 3.89-17.38; $P<0.01)$.

\section{Discussion}

The purpose of this investigation was to evaluate metabolic components and determine appropriate WC cutpoints that are well-matched for this particular population, which has been described as obesity-prone [9] and highly sedentary [18], with high prevalence of hypertension [19] and low grade inflammation [20]. The results demonstrate that IDF/NHLBI/AHA-2009 WC cut-off points overestimate obesity and that the obtained local WC cutpoints are more suited for obesity diagnosis and MRFA.

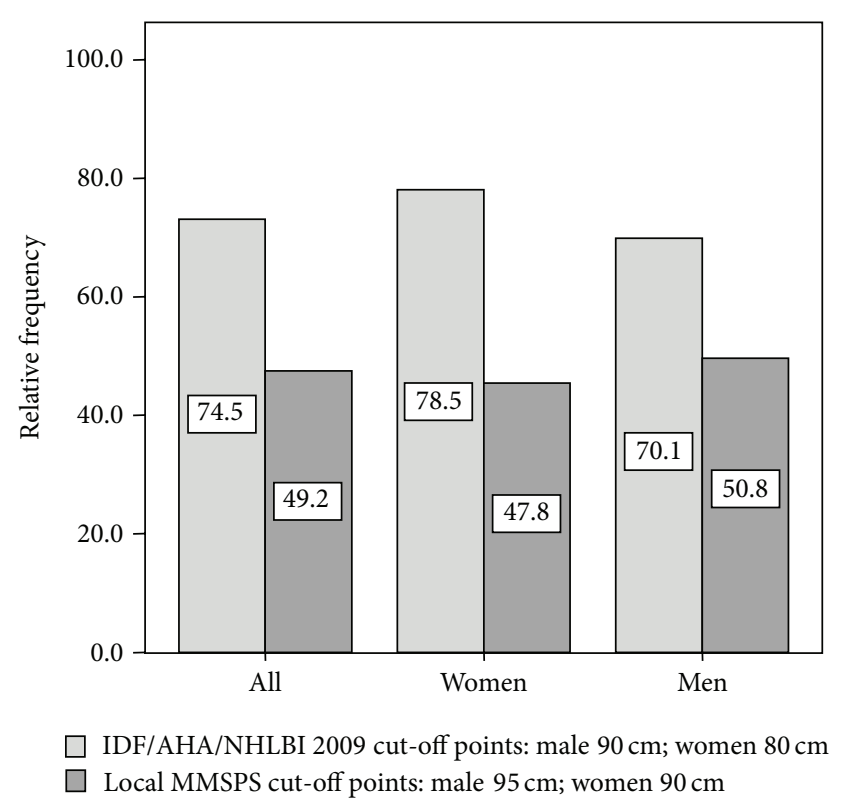

FIGURE 2: Prevalence of abdominal obesity according to the IDF/AHA/NHLBI-2009 and Local MMSPS cut-off points, Maracaibo, 2014.

Reports of an alarming rise on MS have been published in Latin America in the last decade [2, 3, 21]. When analyzing the epidemiologic behavior of its components, low HDL-C and 
TABLE 4: Logistic regression model for risk factors associated with Elevated Waist Circumference (abdominal obesity), Maracaibo, 2014.

\begin{tabular}{|c|c|c|c|c|c|}
\hline & $n$ & $\begin{array}{l}\text { Crude odds ratio } \\
\qquad\left(\mathrm{CI} 95 \%{ }^{\mathrm{a}}\right)\end{array}$ & $P^{\mathrm{b}}$ & $\begin{array}{c}\text { Adjusted odds } \\
\text { ratio }^{c} \\
(\mathrm{CI} 95 \%)\end{array}$ & $P$ \\
\hline \multicolumn{6}{|c|}{ High blood pressure $^{\mathrm{d}}$} \\
\hline Absent & 1199 & 1.00 & - & 1.00 & - \\
\hline Present & 703 & $4.13(3.38-5.05)$ & $<0.01$ & $2.38(1.87-3.05)$ & $<0.01$ \\
\hline \multicolumn{6}{|c|}{ Impaired fasting glucose $^{\mathrm{d}}$} \\
\hline Absent & 1443 & 1.00 & - & 1.00 & - \\
\hline Present & 459 & $2.78(2.23-3.47)$ & $<0.01$ & $1.42(1.08-1.85)$ & 0.01 \\
\hline \multicolumn{6}{|c|}{ High triacylglycerides ${ }^{\mathrm{d}}$} \\
\hline Absent & 1406 & 1.00 & - & 1.00 & - \\
\hline Present & 496 & $3.44(2.75-4.29)$ & $<0.01$ & $1.67(1.29-2.17)$ & $<0.01$ \\
\hline \multicolumn{6}{|c|}{ Low HDL-C ${ }^{\mathrm{d}}$} \\
\hline Absent & 827 & 1.00 & - & 1.00 & - \\
\hline Present & 1075 & $1.94(1.61-2.33)$ & $<0.01$ & $1.60(1.28-1.99)$ & $<0.01$ \\
\hline \multicolumn{6}{|c|}{ Insulin resistance $\mathrm{e}^{\mathrm{e}}$} \\
\hline Absent & 1049 & 1.00 & - & 1.00 & - \\
\hline Present & 853 & $3.55(2.93-4.29)$ & $<0.01$ & $3.10(2.47-3.83)$ & $<0.01$ \\
\hline
\end{tabular}

abdominal obesity are common results in regional studies $[3,9]$. Although the former has been linked to a plausible "American" genetic component [22], the great prevalence of central obesity may be distorted by the application of nonethnic-specific cut-offs points to our population, such as those proposed by IDF using unclear methodology from SubAsian demographics and information $[4,5]$.

The cut-off points in this report are higher than those suggested in the latest MS consensus $(90 \mathrm{~cm}$ for men and $80 \mathrm{~cm}$ for women) and are comparable to those obtained by Aschner et al. [23] in 457 individuals from diverse Latin American cities, as ascertained by measurement of visceral adipose tissue through imaging techniques; they reported a cut-off point of $94 \mathrm{~cm}$ for men and $90-92 \mathrm{~cm}$ for women [23]. In this regard, other South American countries, such as Colombia and Cuba, have published their findings. Gallo et al. [24] determined a WC cut-off point that could discriminate the presence of IR in a Colombian population (using ROC curves and Youden Index for cut-off point selection); they proposed a cut-off point of $92 \mathrm{~cm}$ for men (sensitivity $82.2 \%$ and specificity $70.14 \%$ ) and $84 \mathrm{~cm}$ for women (sensitivity $78.15 \%$ and specificity $73.98 \%$ ). On the other hand, Popa et al. [25] use individuals from the Cuban region of HolguínGranma, selecting a WC cut-off point that could determine the presence of 2 or more MS components (also applying ROC curves and Youden Index as selection determinant); they published a cut-off point of $97 \mathrm{~cm}$ for men (sensitivity $55 \%$ and specificity $91 \%$ ) and $85 \mathrm{~cm}$ for women (sensitivity $87 \%$ and specificity $72 \%$ ) [25].

The significance of determining WC cut-off points according to local sociocultural characteristics is so important that differences in this anthropometrical parameter are not only observed within Latin-American populations, but also between the different ethnic groups in this study [26], demonstrating that several factors can influence the presence of obesity in our sample, and also in our country $[26,27]$. Nevertheless, in spite of the differences observed between cutpoints in each ethnic group, especially between AfroVenezuelans and Amerindians which show the lowest prevalence of obesity in our city, they represent the minority groups in our population and their results do not modify the results obtained in the general population. Consequently, ethnicspecific cut-off points need to be determined in such groups, as well as the description of genetic and environmental factors that could influence the observed differences with studies focused on these minority groups.

There are advantages to using our new cut-offs to define abdominal obesity. First off, we appropriately identify subjects with obesity, which seems to be overdiagnosed in our community when using previously established cutpoints [9] (Figure 2). Secondly, their association with all components of MS in our population as assessed by multivariate analysis aids in the evaluation of cardiometabolic risk, especially with $\mathrm{HBP}$ as previously described by Olinto et al. [28] in Brazilian women. The proposed mechanisms in this relationship are IR and chronic hyperinsulinemia, acting as principal mediators [29]. However, in our study this relation is independent of IR, which coincides with the Olivetti Heart Study [30], a research that suggests that the neuroendocrine abnormalities observed in the sympathetic nervous system are the link between abdominal obesity and elevated high blood pressure. Moreover, in the last decade, new molecules such as adiponectin and leptin have been associated with hypertension, yet more research is needed to truly understand 
TABLE 5: Logistic regression model for multiple risk factor aggregation ${ }^{\dagger}$, Maracaibo, 2014.

\begin{tabular}{|c|c|c|c|c|c|}
\hline & $n$ & $\begin{array}{c}\text { Crude odds ratio } \\
\left(\text { CI } 95 \%^{\mathrm{a}}\right)\end{array}$ & $P^{\mathrm{b}}$ & $\begin{array}{c}\text { Adjusted odds ratio }^{c} \\
(\text { CI 95\%) }\end{array}$ & $P$ \\
\hline \multicolumn{6}{|l|}{ Gender } \\
\hline Female & 992 & 1.00 & - & 1.00 & - \\
\hline Male & 910 & $1.35(1.12-1.62)$ & $<0.01$ & $1.73(1.40-2.15)$ & $<0.01$ \\
\hline \multicolumn{6}{|l|}{ Ethnic groups } \\
\hline Mixed & 1463 & 1.00 & - & 1.00 & - \\
\hline Hispanic white & 300 & $1.16(0.90-1.49)$ & 0.24 & $1.03(0.77-1.38)$ & 0.84 \\
\hline Afro-Venezuelan & 55 & $1.38(0.80-2.36)$ & 0.25 & $1.54(0.84-2.84)$ & 0.16 \\
\hline Amerindian & 73 & $0.57(0.34-0.95)$ & 0.03 & $0.67(0.37-1.21)$ & 0.18 \\
\hline Others & 11 & $1.11(0.34-3.64)$ & 0.87 & $1.22(0.28-5.20)$ & 0.79 \\
\hline \multicolumn{6}{|l|}{ Age groups (years) } \\
\hline$<20$ & 157 & 1.00 & - & 1.00 & - \\
\hline $20-29$ & 512 & $1.13(0.72-1.76)$ & 0.60 & $0.79(0.50-1.27)$ & 0.34 \\
\hline $30-39$ & 354 & $2.39(1.52-3.74)$ & $<0.01$ & $1.47(0.91-2.37)$ & 0.12 \\
\hline $40-49$ & 394 & $5.58(3.59-8.68)$ & $<0.01$ & $3.54(2.21-5.69)$ & $<0.01$ \\
\hline $50-59$ & 306 & $7.04(4.46-11.12)$ & $<0.01$ & $4.44(2.72-7.25)$ & $<0.01$ \\
\hline $60-69$ & 120 & $9.87(5.66-17.22)$ & $<0.01$ & $6.84(3.78-12.38)$ & $<0.01$ \\
\hline$\geq 70$ & 59 & $11.92(5.89-24.14)$ & $<0.01$ & $8.22(3.89-17.38)$ & $<0.01$ \\
\hline \multicolumn{6}{|c|}{ High waist circumference ${ }^{\mathrm{d}}$} \\
\hline Absent & 966 & 1.00 & - & 1.00 & - \\
\hline Present & 936 & $4.59(3.77-5.58)$ & $<0.01$ & $2.56(2.05-3.20)$ & $<0.01$ \\
\hline \multicolumn{6}{|l|}{ Insulin resistance $\mathrm{e}^{\mathrm{e}}$} \\
\hline Absent & 1049 & 1.00 & - & 1.00 & - \\
\hline Present & 853 & $2.74(2.27-3.30)$ & $<0.01$ & $2.30(1.85-2.86)$ & $<0.01$ \\
\hline
\end{tabular}

${ }^{\dagger}$ Defined as $\geq 2$ of the following: high blood pressure, impaired fasting glucose, high triacylglycerides, low HDL-C (dependent variable).

${ }^{a}$ Confidence interval (95\%). ${ }^{b}$ Significance level.

${ }^{c}$ Adjusted for gender, age groups, ethnic groups, high waist circumference, and insulin resistance.

${ }^{\mathrm{d}}$ Defined as $\geq 90.25$ for females and $\geq 95.15 \mathrm{~cm}$ for males.

${ }^{\mathrm{e}}$ Estimated through the HOMA2-IR model; cut-off value: $\geq 2$.

their association with other major players, such as low grade inflammation in obesity-induced hypertension [31]. Nevertheless, IR is the variable typically related to our cutpoints for WC, not only as a component independently related to central obesity but also as a risk factor for the aggregation of MS components, associated with similar likelihood to that entailed by high WC values in this aspect. This harmonizes with the proposal of this anthropometric parameter as a surrogate for the evaluation of IR [32] and it differs with the results published by Onat et al. [33] in 1,534 Turkmen, observing lack of accordance between the presence of insulin resistance and components of MS.

In regards to aging, several reports have suggested that MS prevalence increases with age, reaches a plateau, and decreases in frequency as sarcopenia and low fat mass develop $[34,35]$. However, this phenomenon is not observed in our city, where a steady increase in MS diagnosis is observed in the general population and according to gender [36], coinciding with the proposal that there is a close relationship between age and MS development, associated with defective insulin signaling, hormonal disorders, mitochondrial and endothelial dysfunction, oxidative stress and dysregulation of renin-angiotensin-aldosterone system, and major disorders that seem to coincide and converge with aging $[37,38]$.

It is important to note the limitations ensued by the cross-sectional design of this study, which is why further longitudinal research is necessary to confirm these findings. Moreover, future analyses from our research group will refine the selection methods of metabolic health/sick subjects through data mining techniques that include metabolic and inflammation biomarkers, instead of classic MS components, hypothesizing an enhanced curve plotting with much better sensitivity and specificity. Moreover, the application of visceral adipose index offers a potential alternative to assessment of WC in communities where other imaging methods (such as ultrasound and axial computer tomography) are not available at larger scales.

In conclusion, given the importance of determining population-specific cut-offs, we suggest a WC cut-off point of $90 \mathrm{~cm}$ for women and $95 \mathrm{~cm}$ for men. As shown in the multivariate analysis, these cut-off points are associated with multiple risk aggregation and presence of IR, serving as 
proper candidates for local abdominal obesity and MS diagnosis, fulfilling the call from IDF [5] to provide useful anthropometric information from South American populations.

\section{Abbreviations}

$\begin{array}{ll}\text { AUC: } & \text { Area under the Curve } \\ \text { BMI: } & \text { Body Mass Index } \\ \text { CI: } & \text { Confidence intervals } \\ \text { cm: } & \text { Centimeters } \\ \text { CVD: } & \text { Cardiovascular Disease } \\ \text { HDL-C: } & \text { High density lipoprotein-cholesterol } \\ \text { HOMA2-IR: } & \text { Homeostasis Model Assessment-2 } \\ \text { IDF/NHLBI/AHA: } & \text { International Diabetes Federation, } \\ & \text { National Heart, Lung, Blood Institute, } \\ & \text { American Heart Association } \\ \text { IR: } & \text { Insulin resistance } \\ \text { MMSPS: } & \text { Maracaibo City Metabolic Syndrome } \\ & \text { Prevalence Study } \\ \text { MRFA: } & \text { Multiple risk factor aggregation } \\ \text { MS: } & \text { Metabolic Syndrome } \\ \text { OR: } & \text { Odds ratio } \\ \text { SD: } & \text { Standard deviation } \\ \text { T2DM: } & \text { Type 2 diabetes mellitus } \\ \text { TAG: } & \text { Triacylglycerides } \\ \text { WC: } & \text { Waist circumference. }\end{array}$

\section{Conflict of Interests}

There are no financial or other contractual agreements that might cause conflict of interests.

\section{Acknowledgments}

This work was supported by Research Grant no. CC-0437-1021-09-10 from Consejo de Desarrollo Científico, Humanístico y Tecnológico (CONDES), University of Zulia, and Research Grant no. FZ-0058-2007 from Fundacite-Zulia.

\section{References}

[1] C. Rask-Madsen and C. R. Kahn, "Tissue-specific insulin signaling, metabolic syndrome, and cardiovascular disease," Arteriosclerosis, Thrombosis, and Vascular Biology, vol. 32, no. 9, pp. 2052-2059, 2012.

[2] A. Cuevas, V. Álvarez, and F. Carrasco, "Epidemic of metabolic syndrome in Latin America," Current Opinion in Endocrinology, Diabetes and Obesity, vol. 18, pp. 134-138, 2011.

[3] F. Márquez-Sandoval, G. MacEdo-Ojeda, D. ViramontesHörner, J. D. F. Ballart, J. S. Salvadó, and B. Vizmanos, “The prevalence of metabolic syndrome in Latin America: a systematic review," Public Health Nutrition, vol. 14, no. 10, pp. 17021713,2011

[4] K. G. M. M. Alberti, R. H. Eckel, S. M. Grundy et al., "Harmonizing the metabolic syndrome: a joint interim statement of the international diabetes federation task force on epidemiology and prevention; National heart, lung, and blood institute; American heart association; World heart federation; International atherosclerosis society; And international association for the study of obesity," Circulation, vol. 120, no. 16, pp. 1640-1645, 2009.
[5] K. G. M. M. Alberti, P. Zimmet, and J. Shaw, "The metabolic syndrome-a new worldwide definition," The Lancet, vol. 366, no. 9491, pp. 1059-1062, 2005.

[6] A. A. Mansour, A. A. Al-Hassan, and M. I. Al-Jazairi, "Cutoff values for waist circumference in rural Iraqi adults for the diagnosis of metabolic syndrome," Rural and Remote Health, vol. 7, no. 4, article 765, 2007.

[7] A. Delavari, M. H. Forouzanfar, S. Alikhani, A. Sharifian, and R. Kelishadi, "First nationwide study of the prevalence of the metabolic syndrome and optimal cutoff points of waist circumference in the middle east: the national survey of risk factors for noncommunicable diseases of Iran," Diabetes Care, vol. 32, no. 6, pp. 1092-1097, 2009.

[8] A. A. Motala, T. Esterhuizen, F. J. Pirie, and M. A. K. Omar, "The prevalence of metabolic syndrome and determination of the optimal waist circumference cutoff points in a rural South African community," Diabetes Care, vol. 34, no. 4, pp. 1032-1037, 2011.

[9] V. Bermúdez, M. Pacheco, J. Rojas et al., "Epidemiologic behavior of obesity in the Maracaibo City metabolic syndrome prevalence study," PLoS ONE, vol. 7, no. 4, Article ID e35392, 2012.

[10] V. Bermúdez, R. P. Marcano, C. Cano et al., "The maracaibo city metabolic syndrome prevalence study: design and scope," The American Journal of Therapeutics, vol. 17, no. 3, pp. 288-294, 2010.

[11] Health Statistics, NHANES III Reference Manuals and Reports (CDROM), Centers for Disease Control and Prevention, Hyattsville, Md, USA, 1996, http://www.cdc.gov/nchs/data/ nhanes/nhanes3/cdrom/NCHS/MANUALS/ANTHRO.PDF.

[12] World Health Organization, The World Health Report 2003, http://www.who.int/whr/2003/en/.

[13] V. Bermúdez, J. Rojas, M. S. Martínez et al., "Epidemiologic behavior and estimation of an optimal cut-off point for homeostasis model assessment-2 insulin resistance: a report from a Venezuelan population," International Scholarly Research Notices, vol. 2014, Article ID 616271, 10 pages, 2014.

[14] K. Hara, Y. Matsushita, M. Horikoshi et al., "A proposal for the cutoff point of waist circumference for the diagnosis of metabolic syndrome in the Japanese population," Diabetes Care, vol. 29, no. 5, pp. 1123-1124, 2006.

[15] D. Böhning, W. Böhning, and H. Holling, "Revisiting Youden's index as a useful measure of the misclassification error in metaanalysis of diagnostic studies," Statistical Methods in Medical Research, vol. 3, pp. 1-12, 2008.

[16] N. J. Perkins and E. F. Schisterman, "The inconsistency of "optimal" cutpoints obtained using two criteria based on the receiver operating characteristic curve," The American Journal of Epidemiology, vol. 163, no. 7, pp. 670-675, 2006.

[17] V. Bewick, L. Cheek, and J. Ball, "Statistics review 13: receiver operating characteristics curves," Critical Care, vol. 8, no. 6, pp. 508-512, 2004.

[18] V. J. Bermúdez, J. J. Rojas, E. B. Córdova et al., "International physical activity questionnaire overestimation is ameliorated by individual analysis of the scores," The American Journal of Therapeutics, vol. 20, no. 4, pp. 448-458, 2013.

[19] V. J. Bermúdez, J. Rojas, R. Añez et al., "Prevalence, awareness, management of hypertension and association with metabolic abnormalities: the Maracaibo city metabolic syndrome prevalence study," Revista Latinoamericana de Hipertension, vol. 7, no. 4, pp. 71-79, 2012. 
[20] V. Bermúdez, M. Cabrera, L. Mendoza et al., "High-sensitivity C-reactive protein epidemiological behavior in adult individuals from Maracaibo, Venezuela," Revista Latinoamericana De Hipertension, vol. 8, no. 1, p. 52, 2013.

[21] J. Escobedo, H. Schargrodsky, B. Champagne et al., "Prevalence of the metabolic syndrome in Latin America and its association with sub-clinical carotid atherosclerosis: the CARMELA cross sectional study," Cardiovascular Diabetology, vol. 8, article 52, 2009.

[22] C. A. Aguilar-Salinas, S. Canizales-Quinteros, R. RojasMartfnez et al., "Hypoalphalipoproteinemia in populations of Native American ancestry: an opportunity to assess the interaction of genes and the environment," Current Opinion in Lipidology, vol. 20, no. 2, pp. 92-97, 2009.

[23] P. Aschner, R. Buendía, I. Brajkovich et al., "Determination of the cutoff point for waist circumference that establishes the presence of abdominal obesity in Latin American men and women," Diabetes Research and Clinical Practice, vol. 93, no. 2, pp. 243-247, 2011.

[24] J. A. Gallo, J. E. Ochoa, J. K. Balparda et al., "Puntos de corte del perímetro de la cintura para identificar sujetos con resistencia a la insulina en una población colombiana," Acta Médica Colombiana, vol. 38, pp. 118-126, 2013.

[25] I. R. Popa, O. C. González Sotolongo, and C. A. Arpa Gámez, "Estimated cutoff abdominal circumference of metabolic syndrome diagnosis criterion," Revista Cubana de Medicina Militar, vol. 42, pp. 29-38, 2013.

[26] J. B. Calanche Morales, "Influencias culturales en el régimen alimentario del venezolano," Anales Venezolanos de Nutrición, vol. 22, pp. 32-40, 2009.

[27] J. Rojas, M. Aguirre, M. Velasco, and V. Bermúdez, "Obesity genetics: a monopoly game of genes," The American Journal of Therapeutics, vol. 20, no. 4, pp. 399-413, 2013.

[28] M. T. A. Olinto, L. C. Nacul, D. P. Gigante, J. S. D. Costa, A. M. B. Menezes, and S. Macedo, "Waist circumference as a determinant of hypertension and diabetes in Brazilian women: a population-based study," Public Health Nutrition, vol. 7, no. 5, pp. 629-635, 2004.

[29] J. E. Hall, T. G. Coleman, H. L. Mizelle, and M. J. Smith Jr., "Chronic hyperinsulinemia and blood pressure regulation," American Journal of Physiology: Renal Fluid and Electrolyte Physiology, vol. 258, no. 3, pp. F722-F731, 1990.

[30] A. Siani, F. P. Cappuccio, G. Barba et al., "The relationship of waist circumference to blood pressure: the Olivetti Heart Study," The American Journal of Hypertension, vol. 15, no. 9, pp. 780786, 2002.

[31] V. Kotsis, S. Stabouli, S. Papakatsika, Z. Rizos, and G. Parati, "Mechanisms of obesity-induced hypertension," Hypertension Research, vol. 33, no. 5, pp. 386-393, 2010.

[32] H. Wahrenberg, K. Hertel, B.-M. Leijonhufvud, L.-G. Persson, E. Toft, and P. Arner, "Use of waist circumference to predict insulin resistance: retrospective study," British Medical Journal, vol. 330, no. 7504, pp. 1363-1364, 2005.

[33] A. Onat, G. Hergenç, S. Türkmen, M. Yazici, I. Sari, and G. Can, "Discordance between insulin resistance and metabolic syndrome: features and associated cardiovascular risk in adults with normal glucose regulation," Metabolism: Clinical and Experimental, vol. 55, no. 4, pp. 445-452, 2006.

[34] T. N. Kim and K. M. Choi, "Sarcopenia: definition, epidemiology, and pathophysiology," Journal of Bone Metabolism, vol. 20, pp. 1-10, 2013.
[35] R. Ostan, L. Bucci, E. Cevenini et al., "Metabolic syndrome in the offspring of centenarians: focus on prevalence, components, and adipokines," Age, vol. 35, no. 5, pp. 1995-2007, 2013.

[36] J. Rojas, V. Bermúdez, R. Añez et al., "Comportamiento Epidemiológico del síndrome metabólico en el municipio Maracaibo-Venezuela," Sindrome Cardiometabolico, vol. 3, pp. 31-42, 2013.

[37] A. Rodriguez, D. C. Muller, E. J. Metter et al., "Aging, androgens, and the metabolic syndrome in a longitudinal study of aging," The Journal of Clinical Endocrinology and Metabolism, vol. 92, no. 9, pp. 3568-3572, 2007.

[38] G. Veronica and R. R. Esther, "Aging, metabolic syndrome and the heart," Aging and Disease, vol. 3, no. 3, pp. 269-279, 2012. 


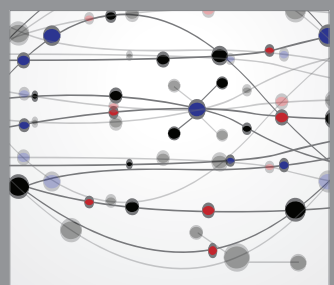

The Scientific World Journal
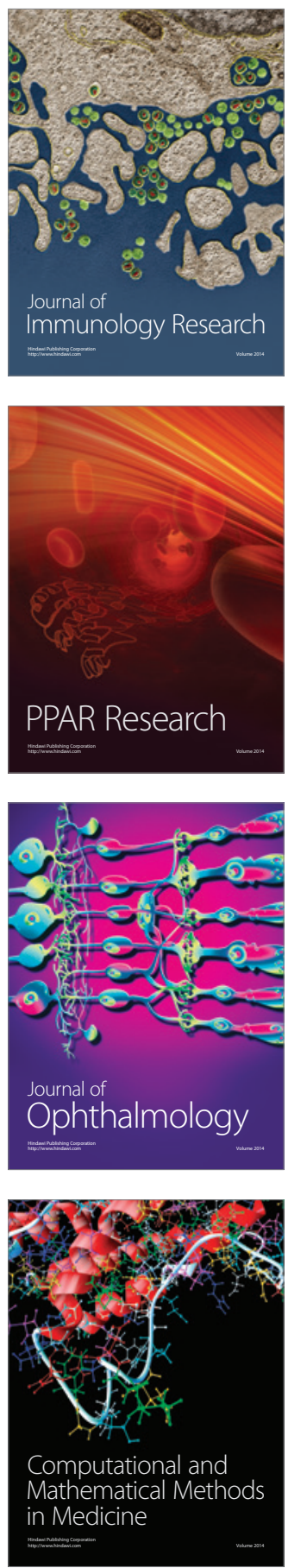

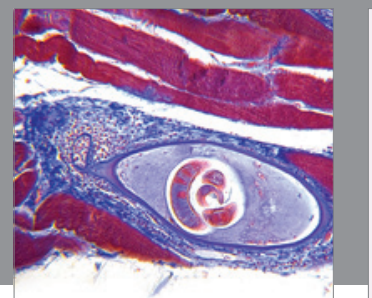

Gastroenterology

Research and Practice
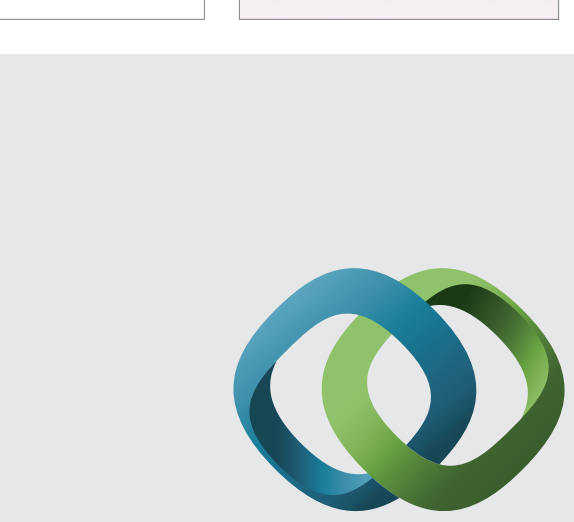

\section{Hindawi}

Submit your manuscripts at

http://www.hindawi.com
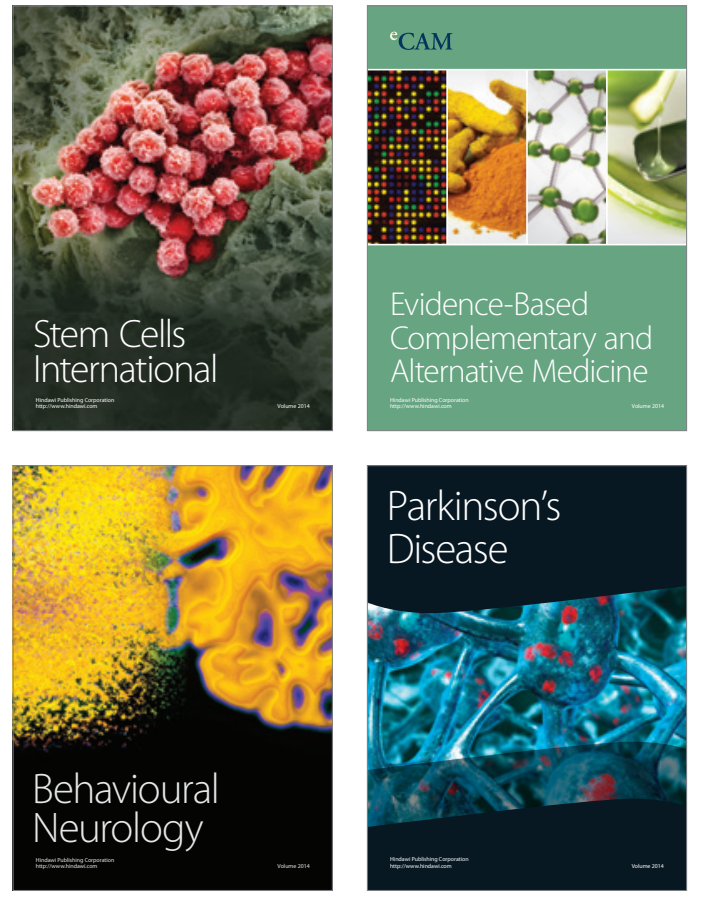
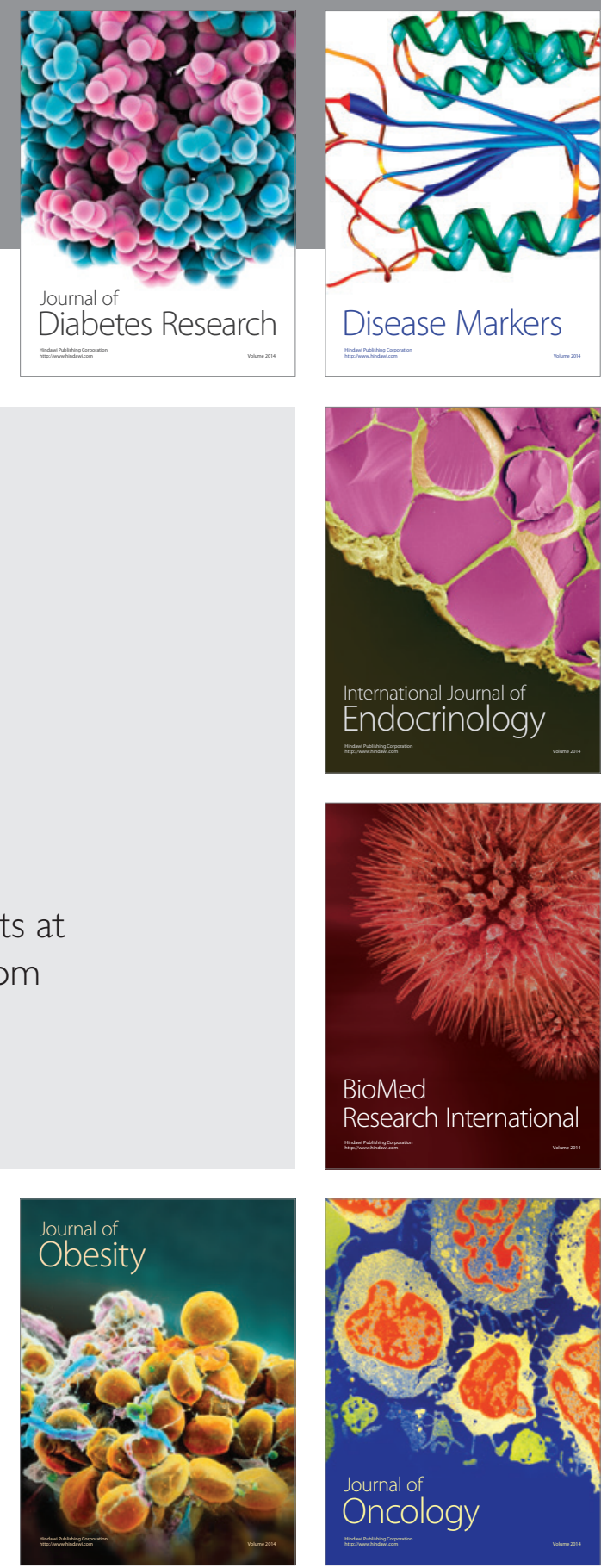

Disease Markers
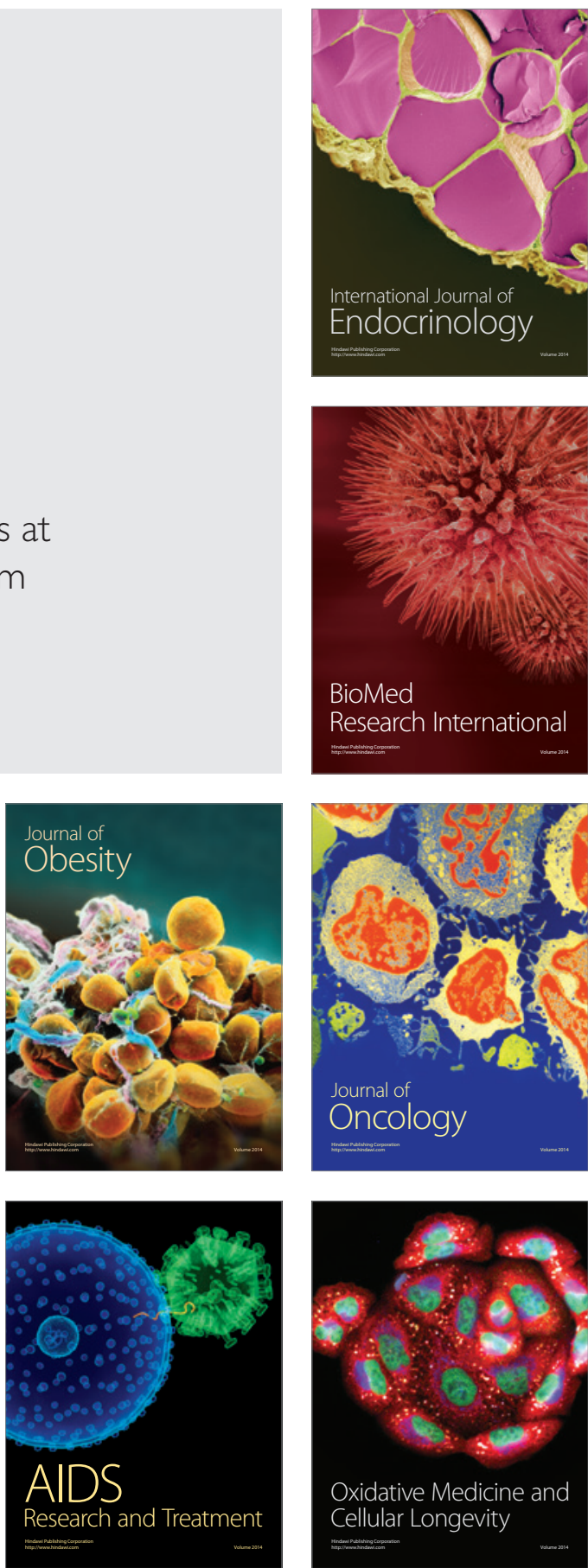